\title{
N.m.r. assignments and temperature-dependent conformational transitions of a mutant trp operator-promoter in solution
}

\author{
Andrew N. LANE \\ National Institute for Medical Research, The Ridgeway, Mill Hill, London NW7 1AA, U.K.
}

\begin{abstract}
A total of 145 protons in the mutant trp operator-promoter sequence CGTACTGATTAATCAGTACG were assigned by one-dimensional and two-dimensional n.m.r. methods. Except at the sites of mutation (underlined), the chemical shifts and other n.m.r. parameters are very similar to those observed in the symmetrized wild-type sequence [Lefèvre, Lane \& Jardetzky (1987) Biochemistry 26, 5076-5090]. Spin-spinrelaxation rate constants of the resolved base protons and intra- and inter-nucleotide nuclear-Overhauserenhancement intensities argue for a sequence-dependent structure similar to that of the wild-type, except at and close to the sites of the mutation. The overall tumbling time as a function of temperature was determined from cross-relaxation rate constants for the H-6-H-5 vectors of the four cytosine residues. The values are consistent with the oligonucleotide maintaining a double-helical conformation over the entire temperature range $5-45^{\circ} \mathrm{C}$, and that internal motions of the bases are of small amplitude on the subnanosecond time scale. The temperature-dependence of chemical shifts, spin-spin-relaxation rate constants and crossrelaxation rate constants show the occurrence of two conformational transitions localized to the TTAA sequence in the centre of the molecule. The thermodynamics of the transition at the lower temperature $\left(t_{\mathrm{m}}=16^{\circ} \mathrm{C}\right)$ were analysed according to a two-state process. The mid-point temperature is about $6{ }^{\circ} \mathrm{C}$ higher than in the wild-type sequence. The conformational transition does not lead to rupture of the Watson-Crick hydrogen bonds, but probably involves changes in the propellor twists of T.A-9 and T.A-10. The second transition occurs at about $40^{\circ} \mathrm{C}$, but cannot be fully characterized. This conformational variability seems to be a property of the sequence TTAA, and may have functional significance in bacterial promoters.
\end{abstract}

\section{INTRODUCTION}

It is well known that the structure of DNA is locally dependent on the base sequence (Calladine, 1982; Dickerson, 1982; Fratini et al., 1982; Patel et al., 1983a,b; Lefèvre et al., 1987; Nilges et al., 1987; Zhou et al., 1987). It is probable that the structures of control sites such as operators and promoters are different from the structures of genomic DNA (Nussinov, 1985). The dependence of the local conformation on sequence may be involved in recognition by specific proteins such as repressors and restriction endonucleases.

DNA is not rigid. There is a gradient of mobility in the molecule from the phosphate backbone to the bases, with the phosphate groups being the most mobile and the bases nearly rigid (Lane et al., 1986; Lefèvre et al., 1987; McCammon \& Harvey, 1987; Nelson et al., 1987). Solution studies of oligodeoxynucleotides have shown that some sequences of DNA have a greater conformational flexibility than others (Patel et al., 1983b; Chou et al., 1984). We have shown that the Pribnow box of the trp promoter undergoes localized conformational transitions in the temperature range $0-45^{\circ} \mathrm{C}$ (Lefèvre et al., 1985a, 1988). It is possible that this conformational variability influences the promoter strength. To test this hypothesis further, a mutant trp operatorpromoter has been synthesized having the sequence CGTACTGATTAATCAGTACG, which differs from the wild-type sequence by inversion of a pair of adjacent bases (underlined). The site of the change corresponds to an operator constitutive mutation, and also to a promoter down mutation (Bennett \& Yanofsky, 1978; Oppenheim et al., 1980). The affinity of the $t r p$ holorepressor for this variant sequence is much less than for the wild-type (Chandler \& Lane, 1988), as expected for a constitutive mutation. Because the base composition and length of the oligonucletoide $(20 \mathrm{bp})$ is the same as in the symmetrized wild-type sequence previously studied by n.m.r. (Lefèvre et al., 1985a,b, 1987), the influence of the mutation at the ends of the Pribnow box on the structure and properties can be compared with the wild-type. Further, it may be possible to relate any differences in conformations between the two sequences to the observed functional effects of the mutations.

Before embarking on a complete description of the conformation in solution, it is essential to determine whether there is a unique structure under a given set of conditions, particularly as it has been shown that the symmetrized wild-type sequence exists in at least three conformations in the temperature range $0-45^{\circ} \mathrm{C}$ (Lefèvre et al., 1988). The subject of the present paper is a characterization of the solution properties of the mutant sequence as a function of temperature by n.m.r., to provide essential information for subsequent detailed structure determination.

\section{MATERIALS AND METHODS}

The $10 \mathrm{bp}$ fragment of DNA (CGTACTGATTAATCAGTACG) was synthesized by using phosphor-

Abbreviations used: NOE, nuclear Overhauser enhancement; NOESY, two-dimensional nuclear-Overhauser-enhancement spectroscopy; COSY, two-dimensional chemical-shift-correlated spectroscopy. 
amidite chemistry on a Beckman synthesizer, and purified by ion-exchange chromatography on a Mono $\mathrm{Q}$ column (Pharmacia) with a gradient of $0-1.5 \mathrm{M}-\mathrm{NH}_{4} \mathrm{HCO}_{3}$. The fractions were collected and freeze-dried. The resulting powder was dissolved in a small volume of buffer $(20 \mathrm{~mm}-$ sodium phosphate buffer, $\mathrm{pH} 7.5$, containing $100 \mathrm{~mm}$ $\mathrm{KCl}$ and $0.1 \mathrm{~mm}$-EDTA), heated at $90^{\circ} \mathrm{C}$ for $10 \mathrm{~min}$ and allowed to cool slowly. The sample was dialysed against the same buffer, and checked by electrophoresis on a $20 \%$ polyacrylamide gel. Finally, the sample was freeze-dried, and dissolved in $0.4 \mathrm{ml}$ of $99.96 \%{ }^{2} \mathrm{H}_{2} \mathrm{O}$ (Aldrich Chemical Co.).

${ }^{1}$ H-n.m.r. spectra were recorded on a Bruker AM 500 n.m.r. instrument equipped with an ASPECT 3000 computer. Spectra were referenced to internal 4,4dimethylsilapentane-1-sulphonate. One-dimensional spectra were recorded by using a $90^{\circ}$ pulse width, 16384 data points over $5000 \mathrm{~Hz}$, with a relaxation delay of $1.4 \mathrm{~s}$, during which the decoupler was set at low power on the ${ }^{1} \mathrm{HO}^{2} \mathrm{H}$ resonance. Where accurate chemical shifts were required, the spectra were enhanced in resolution by using a Lorentz-to-Gauss transformation $(\mathrm{LB}=-2.5$, $\mathrm{GB}=0.25$ ).

Spin-spin-relaxation times $\left(T_{2}\right)$ were measured for singlets by using the Hahn spin-echo sequence, with ten to 12 time delays per experiment, and a relaxation delay of $5 \mathrm{~s}$. Intensities as a function of time were analysed by non-linear regression to a single exponential decay. Truncated driven NOEs were measured according to the method of Wagner \& Wüthrich (1979), with a relaxation delay of $4 \mathrm{~s}$. Phase-sensitive NOESY spectra were recorded by using the time-proportional phase-increment scheme (Marion \& Wüthrich, 1983) at 5, 25 and $40^{\circ} \mathrm{C}$ with mixing times of 70 to $250 \mathrm{~ms}$, with a random variation of the mixing time of $20 \mathrm{~ms}$. Typically, 2048 points in $F 2$ and 512 points in $F 1$ were recorded. The twodimensional matrix was filled with zeros to 2048 points in F1 before Fourier transformation. COSY spectra and double-quantum COSY spectra were recorded in the magnitude mode, by using 2048 points in F2 and 384 points in $F 1$. Exchangeable protons were examined in ${ }^{1} \mathrm{H}_{2} \mathrm{O} /{ }^{2} \mathrm{H}_{2} \mathrm{O}(9: 1, \mathrm{v} / \mathrm{v})$, by using the $1 \overline{3} 31$ pulse sequence of Hore (1983) to suppress the intense solvent signal, with a spectral width of $12000 \mathrm{~Hz}$.

Correlation times were determined from cross-relaxation rate constants for the H-6-H-5 vectors of the four cytosine residues (Lane et al., 1986). The cross-relaxation rate constants were determined at five temperatures from NOE time courses according to the equation:

$$
N O E(t)=(\sigma / \rho)[1-\exp (-\rho t)]
$$

where $\rho$ is the apparent spin-lattice-relaxation rate constant and $\sigma$ is the cross-relaxation rate constant. The latter is related to the correlation time by:

$$
\sigma=\alpha[J(2 \omega)-J(0)] / r^{6}
$$

where $\alpha$. is a constant whose value is $56.92 \AA^{6} \cdot \mathrm{ns}^{-2}, r$ is the internuclear distance [2.45 $\AA$ (i.e. $0.245 \mathrm{~nm}$ ) for H-5 to H-6 of cytosine], and $J(2 \omega)$ and $J(0)$ are spectraldensity functions. The spectral-density functions are defined as:

$$
J(\omega)=\tau /\left(1+\omega^{2} \tau^{2}\right)
$$

where $\tau$ is the correlation time and $\omega$ is the Larmor frequency.

Relaxation parameters were analysed by non-linear regression to the appropriate equations on an Apple Macintosh computer.

\section{RESULTS}

\section{Assignments of resonances}

Fig. 1 shows an n.m.r. spectrum of the oligodeoxynucleotide at $25^{\circ} \mathrm{C}$. The base and $\mathrm{H}-1^{\prime}$ resonances are well resolved. The H-8 resonances (7.6-8.5 p.p.m.) have rather different line widths, which can be ascribed to sequence-dependent variation of the structure (Lefèvre et al., 1987).

The non-exchangeable protons were assigned by a combination of COSY and NOESY spectroscopy, as described by several authors (Hare et al., 1983; Scheek et al., 1984; Weiss et al., 1984). Fig. 2(a) shows a region of an NOESY spectrum at $25^{\circ} \mathrm{C}$, including the base-todeoxyribose $\mathrm{H}-1^{\prime}$ and $\mathrm{H}-3^{\prime}$ connectivities. The sequential connectivities from the $\mathrm{H}-2^{\prime} / \mathrm{H}-2^{\prime \prime}$ to $\mathrm{H}-8 / \mathrm{H}-6$ are shown in Fig. 2(b). At a mixing time of $200 \mathrm{~ms}$ there is significant spin diffusion, as is shown by the presence of four crosspeaks at $F 2=7.03$ p.p.m. These peaks are as follows. The two joined by a line at F2 $=7.03$ p.p.m. are the $\mathrm{H}$ 2" (downfield) and H-2" (upfield) of T-13. The other two cross-peaks are the $\mathrm{H}-2^{\prime \prime}$ (downfield) and $\mathrm{H}-2^{\prime}$ (upfield) of the preceding base, i.e. A-12. The latter peak (largely due to spin diffusion) is of low intensity. The H-2" of T13 connects to the $\mathrm{H}-6$ of $\mathrm{C}-14$ at 7.42 p.p.m., as shown by the vertical arrow. The $\mathrm{H}-2^{\prime}$ of $\mathrm{C}-14$ is found at 1.98 p.p.m. It was possible to assign all of the base protons, $\mathrm{H}-1^{\prime}, \mathrm{H}-2^{\prime}$ and $\mathrm{H}-2^{\prime \prime}$ protons, and most of the $\mathrm{H}-3^{\prime}$ at $25^{\circ} \mathrm{C}$. The correlations of the $\mathrm{H}-\mathrm{1}^{\prime}, \mathrm{H}-2^{\prime}$ and $\mathrm{H}-2^{\prime \prime}$ were checked also by COSY and double-quantum COSY (results not shown). The $\mathrm{H}-4^{\prime}$ protons were assigned by NOESY by using the cross-peaks $\mathrm{H}-\mathrm{l}^{\prime}$ to $\mathrm{H}-4^{\prime}$ and $\mathrm{H}-3^{\prime}$ to $\mathrm{H}-4^{\prime}$. The $\mathrm{H}-5^{\prime}$ and $\mathrm{H}-5^{\prime \prime}$ resonances are all crowded in a small region near 4 p.p.m., and were not assigned. The assignments are given in Table 1 .

Fig. 3 shows one-dimensional n.m.r. spectra of the imino protons at 5,15 and $45^{\circ} \mathrm{C}$. At the lowest

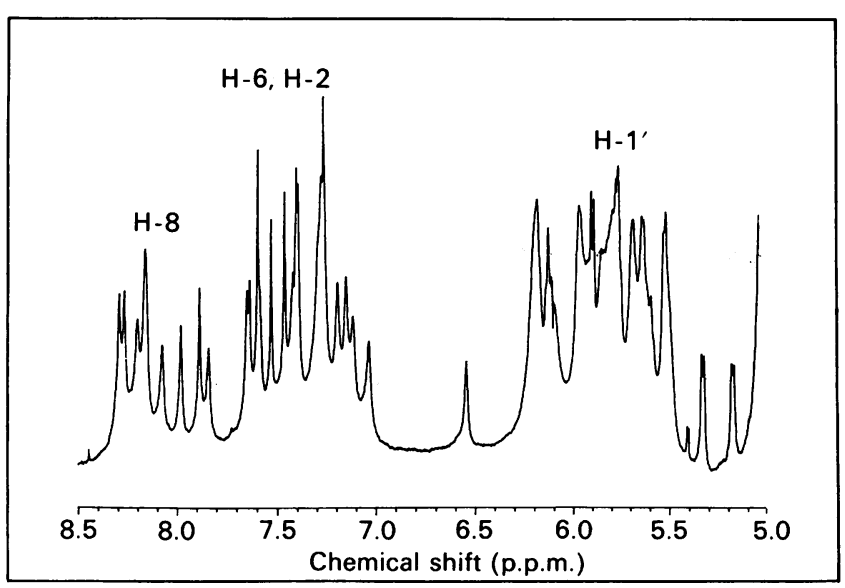

Fig. 1. ${ }^{1} \mathrm{H}$-n.m.r. spectrum of the 20 bp fragment

The spectrum was acquired at $500 \mathrm{MHz}$ and $298 \mathrm{~K}$ as described in the Materials and methods section. Chemical shifts are referenced to internal 4,4-dimethylsilapentane1-sulphonate. A $1 \mathrm{~Hz}$ line broadening was added by exponential multiplication before Fourier transformation. 


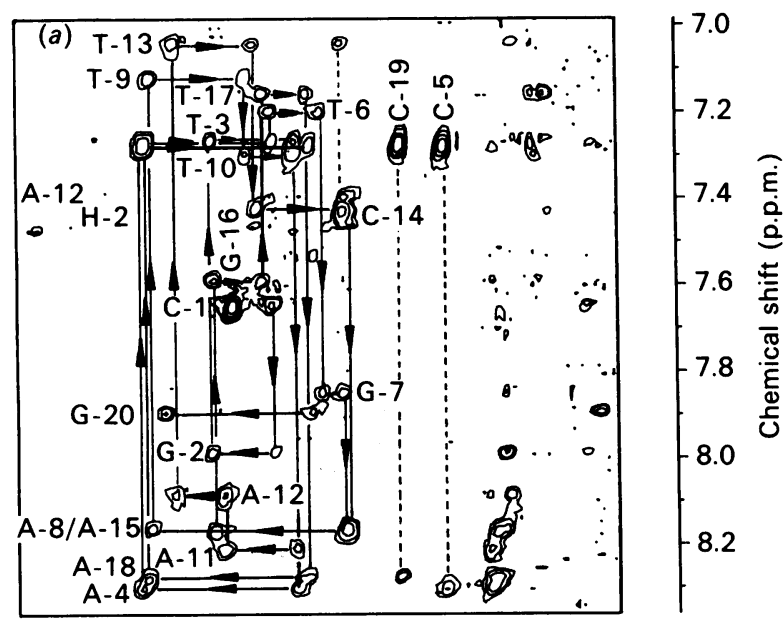

$\begin{array}{llllllllllll}6.6 & 6.4 & 6.2 & 6.0 & 5.8 & 5.6 & 5.4 & 5.2 & 5.0 & 4.8 & 4.6\end{array}$ Chemical shift (p.p.m.)

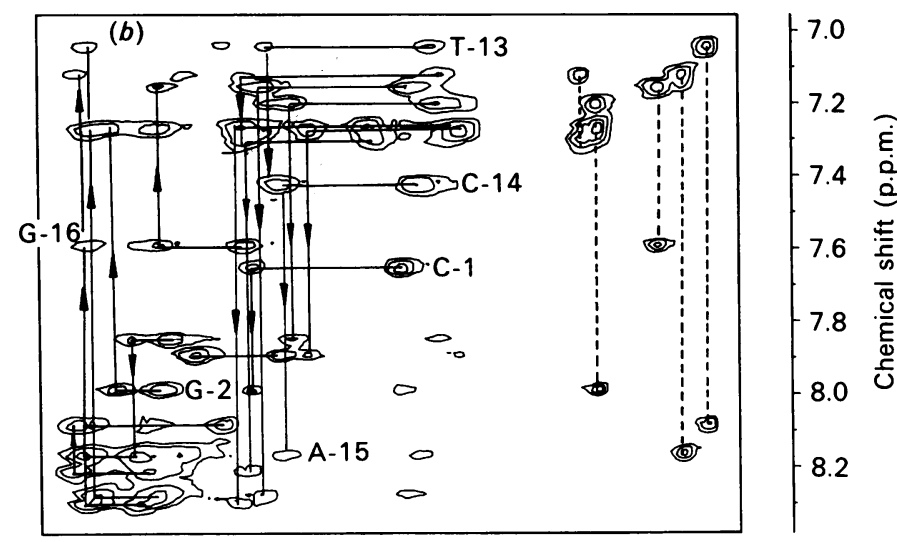

$\begin{array}{llllllllll}3.0 & 2.8 & 2.6 & 2.4 & 2.2 & 2.0 & 1.8 & 1.6 & 1.4 & 1.2\end{array}$

Fig. 2. Phase-sensitive NOESY spectrum of the $20 \mathrm{bp}$ fragment at $25^{\circ} \mathrm{C}$

The spectrum was acquired by using a spectral width of $5000 \mathrm{~Hz}$ in both dimensions, with 2048 points in F2 and 512 points in $F 1$, zero-filled to 2048 points. The free induction decays were multiplied by a Gaussian function with the parameters $\mathrm{LB}=-1 \mathrm{~Hz}$ and $\mathrm{GB}=0.02$ in both dimensions. (a) Sequential connectivities of the $\mathrm{H}-\mathrm{l}^{\prime}$ to base protons, and the $\mathrm{H}-3^{\prime}$ protons. Continuous lines show the $\mathrm{H}-1^{\prime}$-to- $\mathrm{H}-8 / \mathrm{H}-6$ sequential connectivities. Vertical dashed lines show interbase $(\mathrm{H}-8 / 6$ to $\mathrm{H}-5)$ connectivities. (b) Sequential connectivities for the $\mathrm{H}-2^{\prime} /$. $\mathrm{H}-2^{\prime \prime}$ to base protons. Horizonal lines connect cross peaks $\mathrm{H}-2^{\prime}$ and $\mathrm{H}-2^{\prime \prime}$ of a base (intranucleotide NOEs), and vertical lines connect the $\mathrm{H}-2^{\prime \prime}$ of the $5^{\prime}$-base to the $\mathrm{H}-8 / \mathrm{H}-6$ of the $3^{\prime}$-base.

temperature, nine resonances can be resolved, one of which (resonance E) consists of two protons; the molecule retains twofold symmetry in solution. The imino protons of the terminal base-pairs are known to exchange much more readily than internal imino protons, leading to extensive line broadening (Patel \& Hilbers, 1975). At $25^{\circ} \mathrm{C}$, resonance $\mathrm{F}$ has disappeared, owing to exchange broadening with the solvent. Hence resonance $F$ is assigned to $\mathrm{C} \cdot \mathrm{G}-1$. At $45^{\circ} \mathrm{C}$ resonance $\mathrm{G}$ has largely disappeared, and can be assigned to $\mathrm{G} \cdot \mathrm{C}-2$; there is sequential 'fraying' from the ends of the duplex. The remaining imino protons were assigned by onedimensional truncated NOE measurements as previously described (Lefèvre et al., 1985b). Fig. 4 shows a typical NOE difference spectrum obtained by irradiating resonance I, which gives substantial NOEs to resonances A and $\mathrm{E}$. Irradiating resonance $\mathrm{H}$ gives NOEs to resonances $A$ and $D$. As resonances $H$ and $I$ must be $C \cdot G-5$ and $\mathrm{G} \cdot \mathrm{C}-7$, resonance $\mathrm{A}$ must be $\mathrm{T} \cdot \mathrm{A}-6$ as it is the common nearest neighbour. Resonances $D$ and $E$ must therefore contain $\mathrm{A} \cdot \mathrm{T}-4$ and $\mathrm{A} \cdot \mathrm{T}-8$ respectively. The other imino protons were assigned similarly. The assignments of the imino protons are given in Table 2.

The chemical shifts of the imino protons that do not readily exchange decrease linearly with increasing temperature over the range $5-45^{\circ} \mathrm{C}$ (results not shown). The slopes of the temperature-dependences of the chemical shifts are given in Table 2 . The $\mathrm{A} \cdot \mathrm{T}$ imino protons have similar slopes $(\approx-5$ p.p.b./K), whereas the $G \cdot C \mathrm{NH}$ groups have different slopes. The larger slopes are observed for the two terminal bases, and can be ascribed to exchange with solvent. The internal $\mathrm{G} \cdot \mathrm{C}$ base-pairs shows much smaller slopes, as is commonly observed (Early et al., 1981; Chou et al., 1984).

The adenine $\mathrm{H}-2$ resonances were assigned by using NOEs observed on irradiating the imino protons. Also, there is a strong NOE connecting an $\mathrm{H}-2$ resonance at 6.5 p.p.m. to an $\mathrm{H}-2$ at 7.47 p.p.m. that is observed in the NOESY experiment (cf. Fig. 2). There is only one pair of adenine residues that could give rise to an interbase NOE of this kind, namely A-11-A-12. The H-2 of A-11 is expected to resonate far upfield, owing to the ringcurrent shifts of the neighbouring $\mathrm{T} \cdot \mathrm{A}$ and $\mathrm{A} \cdot \mathrm{T}$ basepairs (Arter \& Schmidt, 1976). Also, in the previously studied wild-type sequence, the resonance at 6.6 p.p.m. was assigned to the H-2 of A-11 (Lefèvre et al., 1985b). These assignments were confirmed by one-dimensional NOEs in ${ }^{1} \mathrm{H}_{2} \mathrm{O}$ connecting the adenine $\mathrm{H}-2$ protons to the imino protons of the same base-pair. The assignments of the adenine H-2 resonances are given in Table 1.

\section{Dependence of the overall tumbling time on temperature}

The overall correlation time for tumbling of the molecule was determined by measuring the cross-relaxation rate constants for the $\mathrm{H}-6-\mathrm{H}-5$ vectors of the four cytosine residues as a function of temperature (Lane et al., 1986). Fig. 5(a) shows a typical NOE difference spectrum obtained by irradiating the H-6 of C-5 and $\mathrm{C}-19$ at $25^{\circ} \mathrm{C}$. The dependence of the NOE on the irradiation time is shown in Fig. $5(b)$. From a fit of the NOE intensities to eqn. (1), the cross-relaxation rate constants, $\sigma$, were obtained for each base, at five temperatures $\left(5,15,25,35\right.$ and $\left.40^{\circ} \mathrm{C}\right)$. The cross-relaxation rate constants for all four cytosine residues were identical within experimental error, at least up to $35^{\circ} \mathrm{C}$. At $40^{\circ} \mathrm{C}$ the rate constant for $\mathrm{C}-1$ was slightly lower than those for the other three cytosine residues, presumably owing to 'fraying' at the higher temperature. Because the crossrelaxation rate constants are all the same, the molecule must behave as an isotropic rotor to a good approximation. Further, the apparent correlation time can be 
Table 1. Assignments of the non-exchangeable protons of the $10 \mathrm{bp}$ fragment at $25{ }^{\circ} \mathrm{C}$

The protons were assigned by using a combination of NOESY and COSY as described in the text. Chemical shifts are referenced to internal 4,4-dimethylsilapentane-1-sulphonate. Abbreviation: N.A., not assigned.

\begin{tabular}{|c|c|c|c|c|c|c|c|}
\hline \multirow[b]{2}{*}{ Base } & \multicolumn{7}{|c|}{ Chemical shift (p.p.m.) } \\
\hline & H-8/H-6 & $\mathrm{H}-2 / \mathrm{H}-5 / \mathrm{Me}$ & $\mathrm{H}-\mathbf{1}^{\prime}$ & $\mathrm{H}-2^{\prime}$ & $\mathrm{H}-2^{\prime \prime}$ & $\mathrm{H}-3^{\prime}$ & $\mathrm{H}-4^{\prime}$ \\
\hline $\mathrm{C}-1$ & 7.64 & 5.90 & 5.77 & 2.03 & 2.41 & 4.69 & 4.07 \\
\hline G-2 & 7.97 & - & 5.98 & 2.66 & 2.77 & 4.98 & 4.20 \\
\hline$T-3$ & 7.26 & 1.54 & 5.69 & 2.10 & 2.43 & 4.86 & 4.15 \\
\hline A-4 & 8.30 & 7.40 & 6.21 & 2.71 & 2.86 & 5.04 & 4.45 \\
\hline C-5 & 7.27 & 5.18 & 5.78 & 1.87 & 2.38 & 4.67 & 4.17 \\
\hline$T-6$ & 7.18 & 1.51 & 5.59 & 1.92 & 2.31 & N.A. & 4.06 \\
\hline G-7 & 7.84 & - & 5.51 & 2.65 & 2.75 & 4.99 & 4.33 \\
\hline A-8 & 8.15 & 7.59 & 6.19 & 2.58 & 2.88 & 4.99 & 4.12 \\
\hline $\mathrm{T}-9$ & 7.11 & 1.29 & 5.86 & 1.91 & 2.43 & 4.85 & 4.12 \\
\hline $\mathrm{T}-10$ & 7.28 & 1.59 & 5.69 & 2.08 & 2.41 & 4.89 & 4.15 \\
\hline A-11 & 8.20 & 6.54 & 5.93 & 2.69 & 2.89 & 5.04 & 4.42 \\
\hline A- 12 & 8.08 & 7.46 & 6.10 & 2.51 & 2.89 & 4.96 & 4.45 \\
\hline $\mathrm{T}-13$ & 7.03 & 1.21 & 5.82 & 1.94 & 2.38 & 4.96 & 4.13 \\
\hline C-14 & 7.42 & 5.52 & 5.51 & 1.98 & 2.35 & 4.86 & 4.11 \\
\hline A-15 & 8.16 & 7.40 & 5.98 & 2.72 & 2.86 & 5.02 & 4.37 \\
\hline G-16 & 7.58 & - & 5.81 & 2.43 & 2.68 & 4.88 & 4.37 \\
\hline $\mathrm{T}-17$ & 7.14 & 1.34 & 5.66 & 2.00 & 2.39 & 4.84 & 4.17 \\
\hline A- 18 & 8.27 & 7.53 & 6.20 & 2.68 & 2.84 & 5.02 & 4.42 \\
\hline C- 19 & 7.27 & 5.33 & 5.63 & 1.88 & 2.26 & 4.87 & 4.10 \\
\hline G-20 & 7.89 & - & 6.14 & 2.34 & 2.57 & 4.66 & 4.27 \\
\hline
\end{tabular}

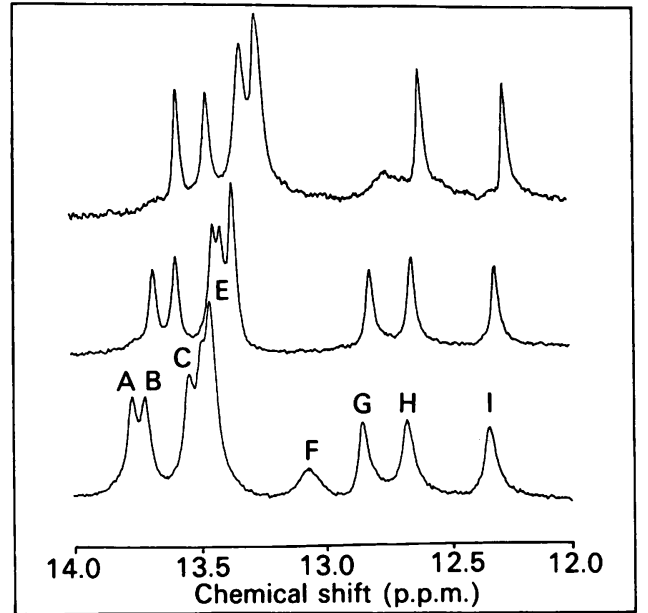

Fig. 3. ${ }^{1} \mathrm{H}-$-n.m.r. spectra of the imino protons of the $20 \mathrm{bp}$ fragment

The spectra were acquired in ${ }^{1} \mathrm{H}_{2} \mathrm{O} /{ }^{2} \mathrm{H}_{2} \mathrm{O}(9: 1, \mathrm{v} / \mathrm{v})$ by using the $1 \overline{3} 3 \overline{1}$ pulse sequence (Hore, 1983) over a spectral width of $12000 \mathrm{~Hz}$, with the use of 16384 points. The free induction decays were multiplied by a $2 \mathrm{~Hz}$ linebroadening exponential before Fourier transformation. Lowest spectrum, $278 \mathrm{~K}$; middle spectrum, $298 \mathrm{~K}$; upper spectrum, $318 \mathrm{~K}$.

calculated from the value of $\sigma$, according to eqn. (3). At $25^{\circ} \mathrm{C}$ the value of $\tau$ is $6 \pm 0.5 \mathrm{~ns}$, which is close to that observed in the wild-type sequence (Lane et al., 1986). An Eyring plot of $\ln (T \cdot \sigma)$ versus $1 / T$ is linear, and the activation energy calculated from the slope is $19 \mathrm{~kJ} / \mathrm{mol}$ (results not shown), which is close to the activation

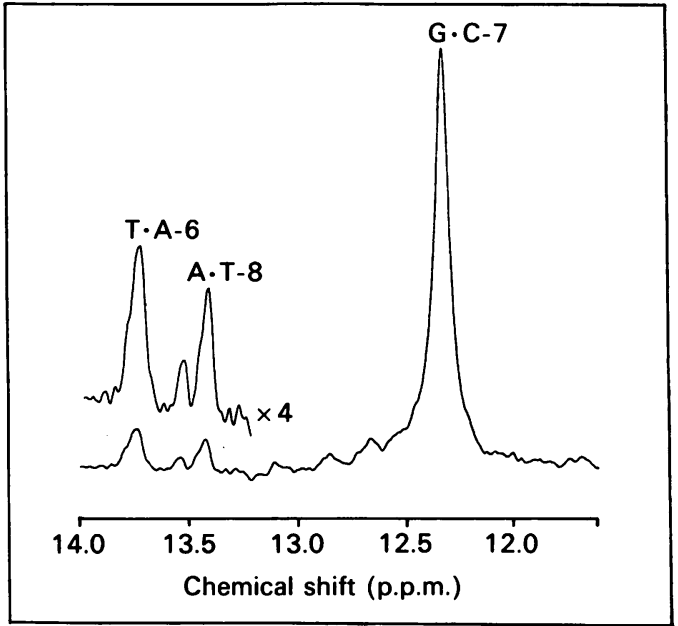

Fig. 4. NOE difference spectrum of the $20 \mathrm{bp}$ fragment in the imino region

Resonance I (G.C-7) was irradiated for $0.3 \mathrm{~s}$ at $283 \mathrm{~K}$. A $10 \mathrm{~Hz}$ line broadening was added to the difference free induction decays before Fourier transformation.

energy of the viscosity of ${ }^{2} \mathrm{H}_{2} \mathrm{O}$ (Wilbur et al., 1976; Lane et al., 1986). Hence the relaxation behaviour of the bases is dominated by the overall tumbling of the oligomer. This point is made more strongly in Fig. 5(c), which shows a Perrin plot of $\sigma$ versus viscosity/temperature. The plot is linear, and the slope is $5.1 \times 10^{4} \pm 0.2 \times$ $10^{4} \mathrm{~s}^{-1} \cdot \mathrm{K} \cdot \mathrm{P}^{-1}$. The slope is related to the size of the molecule by:

$$
\text { Slope }=\left(\alpha / r^{6}\right) V_{\mathrm{h}} / \boldsymbol{R}
$$


Table 2. Assignments and properties of the imino protons of the 20 bp fragment

Imino protons were assigned as described in the text. Chemical shifts are given at $10^{\circ} \mathrm{C}$.

\begin{tabular}{cccc}
\hline Resonance & $\begin{array}{c}\delta_{\mathrm{xH}} \\
\text { (p.p.m.) }\end{array}$ & Assign & $\begin{array}{c}-\mathrm{d} \delta / \mathrm{d} T \\
\text { (p.p.b./K) }\end{array}$ \\
\hline F & 12.98 & C.G-1 & 7.3 \\
G & 12.80 & G.C-2 & 3.2 \\
C & 13.42 & T.A-3 & 5.6 \\
D & 13.40 & A.T-4 & 4.1 \\
H & 12.61 & C.G-5 & 1.8 \\
A & 13.63 & T.A-6 & 4.6 \\
I & 12.25 & G.C-7 & 1.9 \\
E & 13.27 & A.T-8 & 4.5 \\
B & 13.59 & T.A-9 & 6.2 \\
E & 13.27 & T.A-10 & 4.5
\end{tabular}

where $V_{\mathrm{h}}$ is the hydrated volume and $\boldsymbol{R}$ is the gas constant. As $r=2.45 \AA$, the hydrated volume is $16000 \AA^{3}$. Assuming typical values for the partial specific volume and hydration (Cantor \& Schimmel, 1980) and a Perrin factor of 1.2 (Lane et al., 1986), the slope yields an $M_{\mathrm{r}}$ value of about 13000 , close to the chemical $M_{\mathrm{r}}$ of 12000 . Hence the amplitude of internal motions of the bases is small on the subnanosecond time scale. The linearity of the Perrin plot (Fig. 5c) also shows that the molecule does not undergo any gross changes in shape or size in the temperature range $0-45^{\circ} \mathrm{C}$.

\section{Dependence of chemical shifts and line widths on temperature}

The wild-type sequence shows local conformation transitions in the Pribnow box region (TTAACT) in the temperature range $0-45^{\circ} \mathrm{C}$ (Lefèvre et al., 1985a, 1988). It is therefore of interest to determine whether this behaviour is also present in the mutant sequence.

Fig. 6(a) shows the dependence of the chemical shifts of base protons as a function of temperature. The chemical shifts of the $\mathrm{H}-8$ and $\mathrm{H}-6$ resonances decrease essentially linearly over the range $2-50^{\circ} \mathrm{C}$, and with the same slope $(-1.28 \pm 0.11$ p.p.b/K for $\mathrm{H}-8$ and $-1.0 \pm 0.1$ p.p.b/K for $\mathrm{H}-6$ ), with the notable exception of the H-8 of A-11, which actually increases to a plateau value, and the H-6 of T-9, which has a markedly different slope from the other $\mathrm{H}-6$ resonances $(-2.3$ p.p.b./K) (cf. Table 3). This is similar to the behaviour of the base protons in the symmetrized wild-type sequence (Lefèvre et al., 1988). The $\mathrm{H}-2$ resonances of the adenine, which are in the minor groove, show the opposite temperaturedependence to the H-8 resonances. The slope of A-11 $\mathrm{H}-2$ differs markedly from the other $\mathrm{H}-2$ resonances. The assignments of the resonances have also been checked at $5^{\circ} \mathrm{C}$ and $40^{\circ} \mathrm{C}$ by phase-sensitive NOESY experiments, with mixing times of 70 and $100 \mathrm{~ms}$ at $5^{\circ} \mathrm{C}$ and 150 and $200 \mathrm{~ms}$ at $40^{\circ} \mathrm{C}$ (see below).

As the H-8 resonances are all affected equally (except

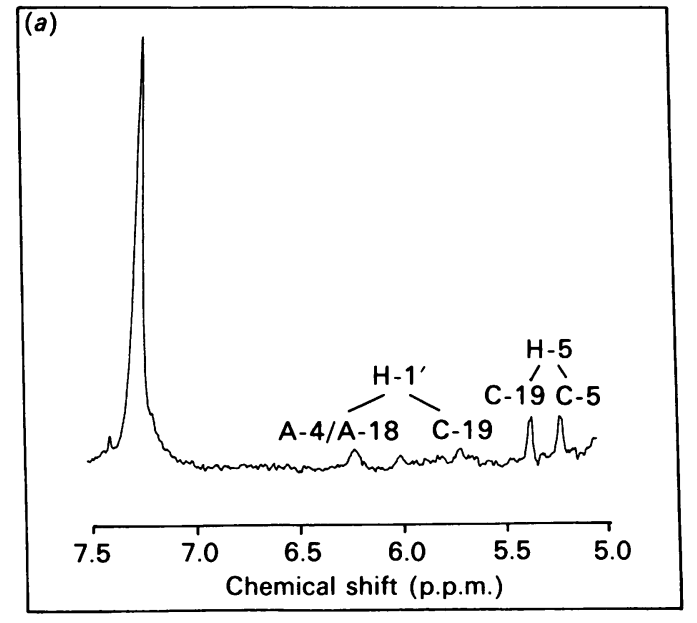

Fig. 5. Overall tumbling time of the $20 \mathrm{bp}$ fragment
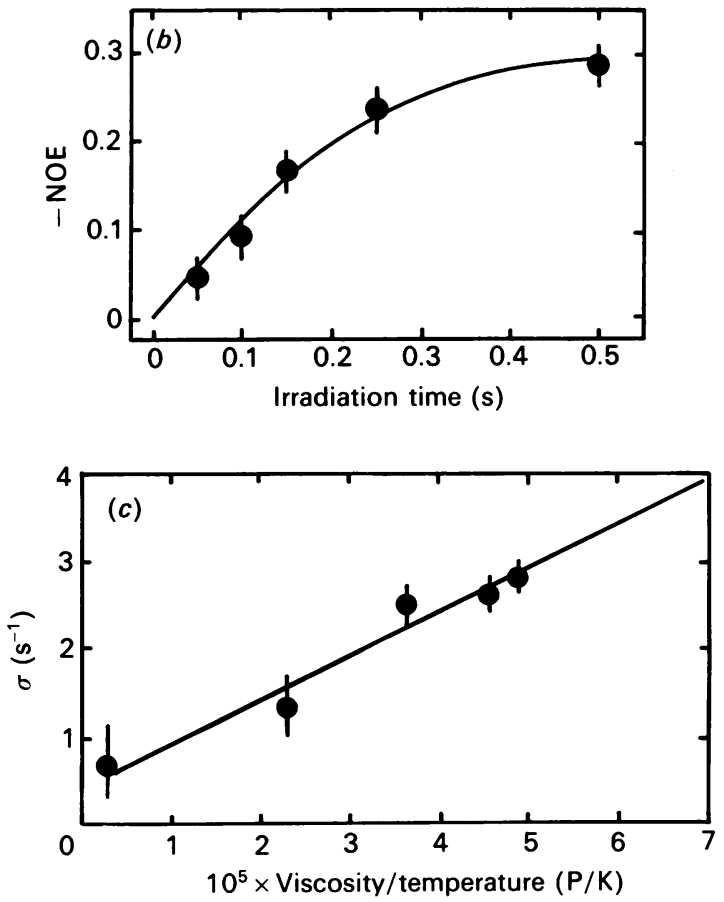

Truncated NOE experiments were performed by irradiating the H-6 resonances of the four cytosine residues for different times and at five different temperatures. (a) NOE difference spectrum obtained on irradiation of C-5 + C-19 H-6 for $100 \mathrm{~ms}$ at $298 \mathrm{~K}$. A $4 \mathrm{~Hz}$ line broadening was added. (b) Dependence of the observed NOE (C-5 H-6-C-5 H-5) on the irradiation time. The continuous line is a fit to eqn. (1), from which the cross-relaxation rate constant for each $\mathrm{H}-6-\mathrm{H}-5$ vector was obtained at each temperature. (c) Dependence of the cross-relaxation rate constant for the H-6-H-5 vectors of C-5, C-14 and C-19 on the ratio of the bulk viscosity to the absolute temperature (eqn. 4). The continuous line has a slope $=5.1 \times 10^{4} \pm 0.2 \times 10^{4} \mathrm{~s}^{-1} \cdot \mathrm{P}^{-1} \cdot \mathrm{K}$. 

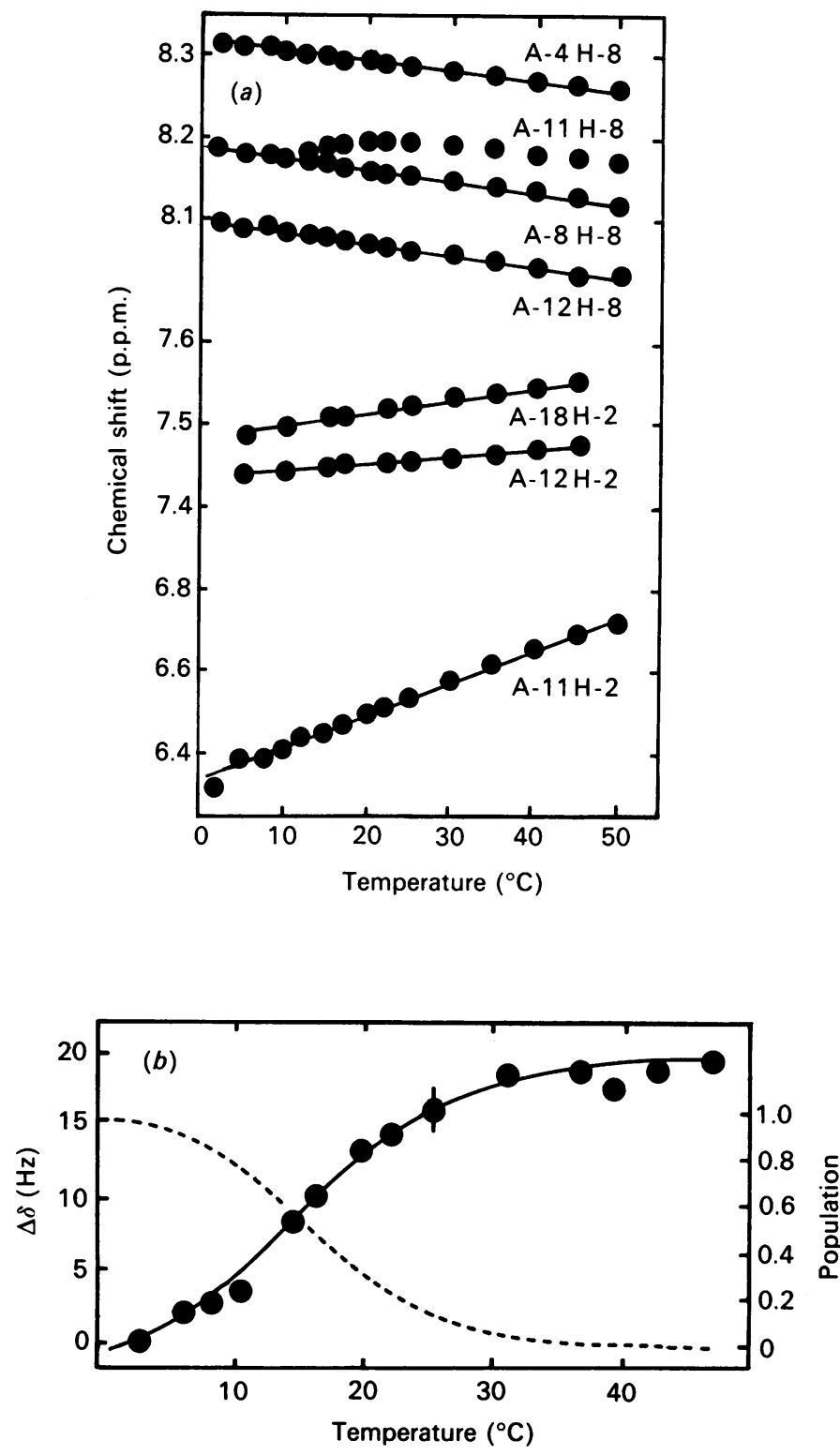

Fig. 6. Dependence of the chemical shifts of base protons on temperature

Chemical shifts were obtained at each temperature from resolution-enhanced spectra (Lorentz-to-Gauss transformation, by using the parameters $\mathrm{LB}=-2.5$ and $\mathrm{GB}=0.25$ ). (a) Plots of absolute chemical shifts versus temperatures. The slopes of the lines are given in Table 3. (b) Difference chemical shift for the $\mathrm{H}-8$ resonance of A-11. The corrected chemical shift was obtained by subtracting out the intrinsic chemical shift as described in the Results section. The continuous line is the non-linear regression fit to eqn. (6). The broken line shows the population of state $I$ as a function of temperature calculated as $\mathrm{P}_{\mathrm{A}}=1 /(1+K)$, by using the parameters given in Table 4 .

A-11 H-8), it is reasonable to suppose that there is an intrinsic temperature-dependence of the chemical shift. If the intrinsic temperature-dependence is subtracted from the chemical shift of A-11 H-8, the curve in Fig. $6(b)$ is obtained (i.e. the excess chemical shift versus tem- perature). The shape of this curve is typical of a simple co-operative transition between two states (I and II):

with:

$$
I \stackrel{K_{1}}{\rightleftharpoons} \text { II }
$$

$$
K_{1}=[\mathrm{II}] /[\mathrm{I}]
$$

The curve in Fig. $6(b)$ can be analysed according to the equation:

and

$$
\Delta \delta=\left(\Delta \delta_{\mathrm{A}}+K_{1} \cdot \Delta \delta_{\mathrm{B}}\right) /\left(1+K_{1}\right)
$$

$$
K_{1}(T)=K_{1}{ }^{0} \cdot \exp \left[(\Delta H / R)\left(1 / T_{0}-1 / T\right)\right.
$$

where $T$ is the absolute temperature, $\Delta H$ the enthalpy change, and the zero refers to a reference temperature (273 K in this case). The line in Fig. 6(b) is the best-fit regression line by using eqns. (6) and (7). The best-fit values of the parameters were $\Delta \delta_{\mathrm{A}}, \Delta \delta_{\mathrm{B}}, K_{1}{ }^{0}$ and $\Delta H$ are given in Table 4 . The values of the chemical-shift differences are well determined, whereas the value of $K_{1}{ }^{0}$ is relatively poorly determined. In the wild-type promoter the first transition was characterized by $K_{1}^{0}=0.023$, $\Delta H=242 \mathrm{~kJ} / \mathrm{mol}$ and $t_{\mathrm{m}}=10^{\circ} \mathrm{C}$. Hence in the mutant promoter the first transition is raised by about $6^{\circ} \mathrm{C}$, and apparently occurs with a lower co-operativity $(146 \mathrm{~kJ} /$ $\mathrm{mol})$. In the wild-type there is a second transition at about $30^{\circ} \mathrm{C}$, which is not observed in the mutant; any second transition must occur at temperatures higher than about $40^{\circ} \mathrm{C}$. Knowing the values of $K_{1}{ }^{0}$ and $\Delta H$ allows the value of $K_{1}$ to be calculated at any temperature, and therefore the populations of states I and II. The temperature-dependence of the population of state $I$ is also shown in Fig. 6(b).

The line widths of most base protons decrease monotonically in the temperature range $0-50^{\circ} \mathrm{C}$, which can be accounted for by the effect of temperature on the overall tumbling time of the molecule. The observed line widths were also checked against the spin-spin-relaxation rate constant determined from Hahn spin-echo experiments at four temperatures (cf. Table 3). There is excellent agreement between the measurements. In the wild-type sequence the line width of the $\mathrm{H}-2$ resonance of A-11 passes through a maximum at about $30^{\circ} \mathrm{C}$. In the mutant sequence, however, the line width of this resonance behaves somewhat differently, as shown in Fig. 7. The line width first decreases in the range $0-15^{\circ} \mathrm{C}$, and then increases up to $40^{\circ} \mathrm{C}$, where there is a maximum. The decrease in line width with increasing temperature indicates that relaxation is dominated by overall tumbling below $15^{\circ} \mathrm{C}$. The subsequent increase in line width can be attributed to exchange broadening, which at $45^{\circ} \mathrm{C}$ amounts to an excess line width of about $8 \mathrm{~Hz}$. Because the line widths of the $\mathrm{H}-2$ resonances of A-4, A-8, A-15 and A-18 all show the same temperature-dependence (i.e. monotonic decrease in line width with increasing temperature), and also that the line widths at low temperature are very similar for all six resonances, it is possible to subtract out the intrinsic temperature-dependence of the line width of A-11 H-2. The line width in the absence of exchange decreases according to:

$L W(T)=L W\left(T_{0}\right)\left(T_{0} / T\right) \cdot \exp \left[-E_{\mathrm{a}}\left(T-T_{0}\right) / R T \cdot T_{0}\right]$

where $L W$ is the line width at temperature $T, L W\left(T_{0}\right)$ is the line width at a reference temperature $T_{0}$ (in this case $278 \mathrm{~K}), E_{\mathrm{a}}$ is the activation energy for the viscosity of ${ }^{2} \mathrm{H}_{2} \mathrm{O}[19 \mathrm{~kJ} / \mathrm{mol}$ (Wilbur et al., 1976), and estimated 
Table 3. Spin-spin-relaxation rates in the 20 bp fragment

$R_{2}$ values were determined from Hahn spin-echo experiments. The error is about $\pm 10 \% . E_{\mathrm{app}}$ is the apparent activation energy for the dependence of $R_{2}$ on temperature as obtained from an Eyring plot. Estimated error on $E_{\text {app. }}= \pm 2 \mathrm{~kJ} / \mathrm{mol}$. Abbreviation: N.D., not determined.

\begin{tabular}{|c|c|c|c|c|c|c|c|}
\hline \multirow[b]{2}{*}{ Base } & \multirow[b]{2}{*}{ Proton } & \multicolumn{4}{|c|}{$R_{2}\left(\mathrm{~s}^{-1}\right)$} & \multirow{2}{*}{$\begin{array}{c}E_{\text {app. }} \\
(\mathrm{kJ} / \mathrm{mol})\end{array}$} & \multirow{2}{*}{$\begin{array}{c}\mathrm{d} \delta / \mathrm{d} T \\
\text { (p.p.b./K) }\end{array}$} \\
\hline & & $278 \mathrm{~K}$ & $288 \mathrm{~K}$ & $298 \mathrm{~K}$ & $313 \mathrm{~K}$ & & \\
\hline A-11 & $\mathrm{H}-2$ & 16.9 & 14 & 22.5 & 32 & * & 8.0 \\
\hline A- 12 & H-2 & 9.9 & 8.0 & 6.4 & 6.2 & $13 \dagger$ & 0.9 \\
\hline A-8 & $\mathrm{H}-2$ & N.D. & N.D. & 7.5 & 4.8 & N.D. & 0.8 \\
\hline A-18 & H-2 & 15.5 & 11.3 & 7.7 & 5.2 & 18 & 1.26 \\
\hline A-4/A-15 & $\mathrm{H}-2$ & 13.5 & 10.1 & 8.0 & 5.5 & 16 & 0.9 \\
\hline A-4 & H-8 & 48 & 33.5 & 23 & 12.0 & 21 & -1.2 \\
\hline A-18 & H-8 & 48 & 34.1 & 16 & 12.2 & 21 & -1.3 \\
\hline A-11 & H-8 & N.D. & N.D. & 19.6 & 25.8 & N.D. & $-1.3 \ddagger$ \\
\hline A-8/A-15 & H-8 & 53 & 30.6 & 27 & 15.7 & 17 & -1.6 \\
\hline A-12 & H-8 & 52 & 37.7 & 25 & 20.4 & 16 & -1.4 \\
\hline G-2 & H-8 & 37 & 30.4 & 15.4 & 12.0 & 18 & -1.2 \\
\hline G-20 & H-8 & 35 & 25.1 & 13.3 & 8.2 & 24 & -1.1 \\
\hline G-7 & H-8 & 35 & 26.9 & 17.4 & 11.9 & 18 & -1.3 \\
\hline
\end{tabular}

* $E_{\text {app. }}$ is negative in the range $5-25^{\circ} \mathrm{C}$.

+ From 5 to $25^{\circ} \mathrm{C}$.

$\ddagger$ Slope from 30 to $50^{\circ} \mathrm{C}$.

Table 4. Thermodynamics of the conformational transition in the Pribnow box

The parameters $\Delta \delta_{\mathrm{A}}, \Delta \delta_{\mathrm{B}}, K_{1}^{0}$ and $\Delta H$ were obtained by non-linear regression to eqns. (6) and (7) as described in the text. The value of $t_{\mathrm{m}}$ was calculated by using eqn. (7) with $K_{1}=1.0$.

\begin{tabular}{lcc}
\hline Parameter & Dimension & Value \\
\hline$\Delta \delta_{\mathrm{A}}$ & $\mathrm{Hz}$ & $-1.3 \pm 1.2$ \\
$\Delta \delta_{\mathrm{B}}$ & $\mathrm{Hz}$ & $20.4 \pm 0.6$ \\
$K_{1}{ }^{0}$ & - & $0.027 \pm 0.016$ \\
$\Delta H$ & $\mathrm{~kJ} / \mathrm{mol}$ & $149 \pm 20$ \\
$t_{\mathrm{m}}$ & ${ }^{\circ} \mathrm{C}$ & $16 \pm 1$
\end{tabular}

also from Eyring plots of the line widths for the adenine $\mathrm{H}-2$ resonances] and $\boldsymbol{R}$ is the gas constant. This expected line width was then subtracted from the observed linewidth, by using a reference value of $5.5 \mathrm{~Hz}$ for A-11 H-2 (cf. Table 3). The corrected linewidths are also shown in Fig. 7.

For a pure two-state transition, the line width would pass through a maximum at about the mid-point temperature. However, the excess line width of A-11 H-2 only reaches a maximum at about $40^{\circ} \mathrm{C}$, and is actually quite small at $16^{\circ} \mathrm{C}$, the mid-point temperature of the transition reported by the $\mathrm{H}-8$ of the same base. Therefore there must be a second transition whose mid-point temperature is higher than about $35-40^{\circ} \mathrm{C}$. The maximum in the plot of linewidth versus temperature for the wild-type sequence occurs at $30^{\circ} \mathrm{C}$. Indeed, the whole curve in the mutant sequence is shifted by about $10^{\circ} \mathrm{C}$ to higher temperatures. Apparently the mutation makes the low-temperature structure more stable. As in the wildtype sequence (Lefèvre et al., 1985a, 1988), the other bases show no evidence of any conformational transitions in the range $5-50^{\circ} \mathrm{C}$.

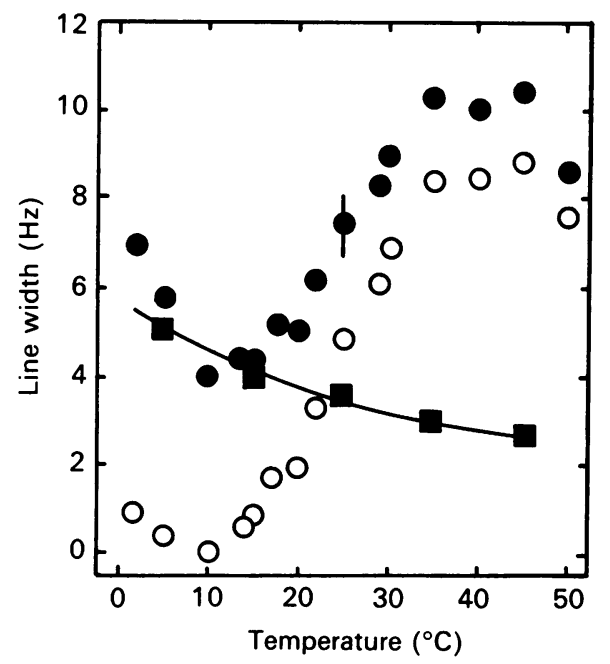

Fig. 7. Dependence of line widths of base protons on temperature

Line widths of resolved resonances were obtained at each temperature from transformed spectra. The width of the resonance of the reference 4,4-dimethylsilapentane-1sulphonate line was subtracted from the apparent width to account for the effects of added line broadening and residual magnetic field inhomogeneity. This procedure gives good agreement with line widths calculated from measured $R_{2}$ values, where appropriate (cf. Table 3). The line width of A-11 H-2 was also corrected by subtracting the intrinsic temperature-dependence as described in the text. $\mathrm{O}, \mathrm{H}-2$ of $\mathrm{A}-11 ; \mathbf{\square}, \mathrm{H}-2$ of $\mathrm{A}-4 ; \mathrm{O}, \mathrm{H}-2$ of $\mathrm{A}-11$ corrected.

\section{Effect of temperature on the imino protons}

It is possible that the observed conformational transitions arise from local melting in the A.T-rich region in the Pribnow box, which in the mutant is $6 \mathrm{bp}$ long compared with $4 \mathrm{bp}$ in the wild-type sequence. 
However, in the wild-type sequence the imino protons of the A.T base-pairs in the Pribnow box were more stable to exchange than were those of other A.T base-pairs (Lefèvre et al., 1985b). The effect of raising the temperature on the spectrum of the imino proton region was shown in Fig. 3. At the lowest temperature all ten imino protons are present, whereas at $25^{\circ} \mathrm{C}$ the imino protons of C.G-1 have disappeared owing to exchange with solvent, and by $45^{\circ} \mathrm{C}$ the imino proton of $\mathrm{G} \cdot \mathrm{C}-2$ is almost completely exchange-broadened. This is the wellknown phenomenon of 'fraying' at the ends (Patel et al., 1983 ; Chou et al., 1984). Nevertheless, the relative areas of the A.T peaks and $\mathrm{G} \cdot \mathrm{C}$ peaks at $45^{\circ} \mathrm{C}$ indicate that very little exchange of internal $\mathrm{A} \cdot \mathrm{T}$ imino protons has occurred. Therefore the central A.T base-pairs are not especially susceptible to exchange with solvent. Indeed, the central A.T base-pairs retain their Watson-Crick hydrogen-bonding up to the highest temperatures used, indicating that the entire molecule, apart from the ends, remains largely double-stranded at temperatures where the localized conformational changes are observed.

\section{Relaxation rate measurements}

That the conformational transition also includes A-12 is evident from the relaxation behaviour of the H-8 and H-2 protons of this residue. Except for A-11, A-12 and G-20 the $R_{2}$ values for the $\mathrm{H}-8$ and $\mathrm{H}-2$ resonances decrease with increasing temperature according to that expected from decreased viscosity. The apparent activation energies $\left(E_{\text {app. }}\right)$ determined from plots of $\ln \left(R_{2} \cdot T\right)$ versus $1 / T$ (Eyring plot, not shown) are in the range $16-20 \mathrm{~kJ} / \mathrm{mol}$ (cf. Table 3 ). Because $R_{2}$ is proportional to the sum of the inverse sixth power of the interproton distances, the Eyring plot will be linear only if that sum does not change with temperature. Further, the apparent activation energy is expected to be about $19 \mathrm{~kJ} / \mathrm{mol}$ for a rigid molecule. The $R_{2}$ values for the H-2 and H-8 of A-12, however, decrease between 5 and $25^{\circ} \mathrm{C}$, and then remain nearly constant or even increase between 25 and $40^{\circ} \mathrm{C}$. This behaviour is substantiated by measurements of the line widths as a function of temperature (see above). Further, although the $R_{2}$ values of all the adenine $\mathrm{H}-8$ and adenine $\mathrm{H}-2$ resonances are very similar at $5{ }^{\circ} \mathrm{C}$, which is well below the transition temperature for the first conformational change, the $\boldsymbol{R}_{\mathbf{2}}$ values for the base protons of A-11 and A-12 are significantly larger at higher temperatures than for the other adenine residues. This indicates that there is a relatively uniform structure at low temperatures, which changes into a second structure at around $16^{\circ} \mathrm{C}$, involving changes in the stacking and orientation of A-11 and A-12 (and presumably T-9 and T-10). However, the relaxation behaviour of A-12 suggests that this base experiences changes in conformation at temperatures higher than about $15^{\circ} \mathrm{C}$, because the $R_{2}$ values level off above about $25^{\circ} \mathrm{C}$.

The temperature-dependence of the conformational changes involving A-11 and A-12 was examined further by measuring the cross-relaxation rate constant for the A-11 H-2-A-12 H-2 vector, which depends on the distance between the two bases.

Table 5 shows the dependence of $\sigma(\mathrm{A}-11 \mathrm{H} 2-\mathrm{A}-12$ $\mathrm{H}-2)$ on the temperature. The internuclear distance, $r$, is related to $\sigma$ by:

$$
r=\{(\alpha / \sigma)[6 J(2 \omega)-J(0)]\}^{\frac{1}{6}}
$$

Table 5. Dependence of the cross-relaxation rate constant for the A-11 H-2-A-12 H-2 vector on temperature

The cross-relaxation rate constant was determined from NOE build-up curves as described in the text. Correlation times $\tau$ are taken from Fig. 5. The apparent distance $r_{\text {app. }}$ was evaluated by using eqn. (9). The estimated error on the correlation time is $\pm 10 \%$, and on $\sigma \pm 15 \%$. The error on $r_{\text {app. }}$ is then about $4 \%$.

\begin{tabular}{lccc} 
Temp. (K) & $\tau(\mathrm{ns})$ & $-\sigma\left(\mathrm{s}^{-1}\right)$ & $r_{\text {app. }}(\AA)$ \\
\hline 278 & 13.4 & 0.95 & 3.05 \\
283 & 11.1 & 0.75 & 3.07 \\
288 & 9.7 & 0.41 & 3.32 \\
298 & 6.5 & 0.34 & 3.25 \\
308 & 5.3 & 0.23 & 3.31 \\
313 & 4.8 & 0.23 & 3.25 \\
318 & 4.1 & 0.12 & 3.53
\end{tabular}

where $J(\omega)$ is defined in eqn. (3). The correlation time was determined from the cross-relaxation rate constant for the H-6-H-5 vectors of the four cytosine residues (see above). The apparent separation between the $\mathrm{H} 2$ protons of $\mathrm{A}-11$ and $\mathrm{A}-12$ is $3.05 \pm 0.1 \AA$ at $5^{\circ} \mathrm{C}$ rising to $3.3 \pm 0.1 \AA$ in the range $15-35^{\circ} \mathrm{C}$. These calculations were made assuming that the correlation time for this vector is equal to those for the cytosine $\mathrm{H}-6-\mathrm{H}-5$ vectors. It cannot be ruled out that the bases A-11 and A-12 are more mobile than the other bases in the molecule. However, if internal motions of these bases were responsible for the change in the cross-relaxation rate constant, the internal motion would have to become relatively slower as the temperature is increased. Further, an Eyring plot of the data in Table 5 yields an apparent activation energy of $33 \mathrm{~kJ} / \mathrm{mol}$, which is much larger than expected for effects of temperature on viscosity alone. The simplest interpretation of the data is that A-11 and A-12 undergo conformational changes in the range $5-45^{\circ} \mathrm{C}$.

According to Fig. 6(b) and the data in Table 5, at low temperatures (i.e. lower than about $10^{\circ} \mathrm{C}$ ), A-11 and A12 are in state $\mathrm{I}$, so that the apparent distance between the $\mathrm{H}-2$ protons is close to the true value in state I. Above about $20^{\circ} \mathrm{C} \mathrm{A}-11$ is mainly in state II, so that the apparent distance at $25^{\circ} \mathrm{C}$ is a good estimate of the interproton distance in state II. At higher temperatures $\left(45^{\circ} \mathrm{C}\right)$ the apparent distance increases again (cf. Table 5), even though the transition between states I and II is more than $99 \%$ complete. This is consistent with the effects of temperature on the line widths of A-11 H-2 (cf. Fig. 7), which continues to rise in the range $25-45^{\circ} \mathrm{C}$. Hence there must be a second transition at temperatures higher than about $40{ }^{\circ} \mathrm{C}$.

The small distance of $3.05 \AA$ in state I requires a significant differential propellor twisting of the bases A11 and A-12; assuming an axial rise of $3.4 \AA$ the distance would be about $3.8 \AA$ in the absence of propellor twisting. Further, the increase in distance would cause a decrease of about $45 \%$ in the line widths of the $\mathrm{H}-2$ resonances of A-11 and A-12, contrary to what is observed. This further indicates that the increasing line width as the temperature is raised arises from exchange-broadening due to the conformational change. 


\section{DISCUSSION}

Most of the chemical shifts in the mutant sequence are very similar to those observed for the symmetrized wildtype sequence previously studied (Lefevre et al., 1985b, 1987). The exceptions are at the sites of the mutation, which to a first approximation can be ascribed to the difference in ring-current fields experienced by these residues owing to the altered sequence (Arter \& Schmidt, 1976; Giessner-Prettre \& Pullman, 1987; van de Ven \& Hilbers, 1988). The similarity of the chemical shifts argues for a similar structure, except at and immediately neighbouring the mutation sites. More important is the observation that the pattern of NOE intensities is similar for the two sequences. Further, NOE intensities and spin-spin-relaxation rates show that both wild-type and mutant sequences possess sequence-dependent variation of the local structure.

At low temperatures the structure is relatively uniform, and there is evidence that there is a single (possibly averaged) structure. The dependence of the chemical shifts and line widths, as well as NOE intensities, on temperature clearly shows the presence of a conformational transition at about $16^{\circ} \mathrm{C}$, which involves the central TTAA residues; the remainder of the molecule does not undergo substantial changes in conformation at this temperature. The observed conformational transition probably includes changes in the stacking of $\mathrm{A} \cdot \mathrm{T}-11$ with $\mathrm{A} \cdot \mathrm{T}-12$ and $\mathrm{T} \cdot \mathrm{A}-9$. There may also be changes in the propellor twists of these residues, according to the observed variation of the distance between the $\mathrm{H}-2$ protons of A-11 and A-12. The transition does not involve significant strand separation, because the imino protons do not exchange significantly up to at least $45^{\circ} \mathrm{C}$, nor does the chemical shift of A-12 H-2 move close to the single-stranded state. Further, there is no evidence for large conformational transitions such as 'melting'. Hence the transition at $16^{\circ} \mathrm{C}$ is localized to a few basepairs in the centre of the molecule.

The temperature-dependent variation of the line width of A-11 H-2, however, shows that there must be a second transition occurring at temperatures higher than about $35^{\circ} \mathrm{C}$. This transition could not be characterized further because of possible strand separation occurring at temperatures above $50^{\circ} \mathrm{C}$. Nevertheless, the behaviour of the central TTAA core of the mutant is qualitatively similar to that of the wild-type oligomer.

It is noteworthy that both transitions occur at higher temperatures than in the wild-type sequence (Lefèvre et al., 1988), even though the mutant has a stretch of six A. T base-pairs in the centre, compared with four in the wild-type. These conformational transitions seem to be unrelated to the lower stability of A.T base-pairs compared with G.C base-pairs, as probed by the rate of enchange of imino protons (Lefèvre et al., 1985b). We have previously suggested that the conformational properties of the TTAA sequence may be related to promoter function. Specifically, the conformational instability of this and other related sequences may be involved in the initial conformational change in the Pribnow box region of promoters required for the initiation of transcription. Promoters that more readily undergo the transitions (i.e. low mid-point temperature) should be stronger promoters than those promoters that have sequences less susceptible to conformational transitions (i.e. high mid-point temperatures) (Lefèvre et al.,
$1985 a, 1988)$. It is interesting that the sequence studied here should be a promoter down mutant (Oppenheim et al., 1980).

However, a more detailed description of the conformational changes must await a thorough examination of the structure of this oligonucleotide.

This work was supported by the Medical Research Council (U.K.). I am most grateful to Brian Peck for the synthesis and purification of the oligonucleotide, to Dr. J. Feeney for support and helpful discussions, and to Dr. T. W.-M. Fan for critical appraisal of the manuscript.

\section{REFERENCES}

Arter, D. B. \& Schmidt, P. G. (1976) Nucleic Acids Res. 3, $1437-1447$

Bennett, G. N. \& Yanofsky, C. (1978) J. Mol. Biol. 121 179-192

Calladine, C. R. (1982) J. Mol. Biol. 161, 343-352

Cantor, C. R. \& Schimmel, P. R. (1980) Biophysical Chemistry, Part 2: Techniques for the Study of Biological Structure and Function, pp. 549-590, W. H. Freeman, San Francisco

Chandler, L. R. \& Lane, A. N. (1988) Biochem. J. 250, 925-928

Chou, S. H., Wemmer, D. E., Hare, D. R. \& Reid, B. R. (1984) Biochemistry 22, 2257-2262

Dickerson, R. E. D. (1982) J. Mol. Biol. 166, 419-442

Early, T. A., Kearns, D. R., Hillen, W. \& Wells, R. D. (1981) Biochemistry 20, 3756-3764

Fratini, A. V., Kopka, M. L., Drew, H. R. \& Dickerson, R. E. (1982) J. Biol. Chem. 257, 14686-14707

Giessner-Prettre, C. \& Pullman, B. (1987) Q. Rev. Biophys. 20, 113-172

Hare, D. R., Wemmer, D. E., Chou, S. H., Drobny, G. \& Reid, B. R. (1983) J. Mol. Biol. 171, 319-336

Hore, P. J. (1983) J. Magn. Reson. 55, 283-300

Lane, A. N., Lefèvre, J.-F. \& Jardetzky, O. (1986) J. Magn. Reson. 66, 201-218

Lefèvre, J.-F., Lane, A. N. \& Jardetzky, O. (1985a) FEBS Lett. $190,37-40$

Lefèvre, J.-F., Lane, A. N. \& Jardetzky, O. (1985b) J. Mol. Biol. 185, 689-699

Lefèvre, J.-F., Lane, A. N. \& Jardetzky, O. (1987) Biochemistry 26, 5076-5090

Lefèvre, J.-F., Lane, A. N. \& Jardetzky, O. (1988) Biochemistry 27, 1086-1093

Marion, D. \& Wüthrich, K. (1983) Biochem. Biophys. Res. Commun. 124, 774-783

McCammon, J. A. \& Harvey, S. C. (1987) Dynamics of Proteins and Nucleic Acids, pp. 105-114, Cambridge University Press, Cambridge

Nelson, H. C. M., Finch, J. T., Bonaventura, F. L. \& Klug, A. (1987) Nature (London) 330, 221-226

Nilges, M., Clore, G. M., Gronenborn, A. M., Piet, N. \& McLaughlin, L. W. (1987) Biochemistry 26, 3734-3744

Nussinov, R. (1985) J. Theor. Biol. 115, 179-189

Oppenheim, D. S., Bennett, G. N. \& Yanofsky, C. (1980) J. Mol. Biol. 144, 133-142

Patel, D. J. \& Hilbers, C. W. (1975) Biochemistry 14, 2651-2656

Patel, D. J., Ikuta, S., Kozlowski, S. A. \& Itakura, K. .(1983a) Proc. Natl. Acad. Sci. U.S.A. 80, 2184-2188

Patel, D. J., Kozlowski, S. A. \& Bhatt, R. (1983b) Proc. Natl. Acad. Sci. U.S.A. 80, 3908-3912 
Scheek, R. M., Boelens, R., Russo, N., van Boom, J. H. \& Kaptein, R. (1984) Biochemistry 23, 1371-1376

van de Ven, F. J. M. \& Hilbers, C. W. (1988) Nucleic Acids Res. 16, 5713-5726

Wagner, G. \& Wüthrich, K. (1979) J. Magn. Reson. 33, $675-680$
Weiss, M. A., Patel, D. J., Sauer, R. T. \& Karplus, M. (1984) Proc. Natl. Acad. Sci. U.S.A. 81, 130-134

Wilbur, D. W., DeFries, T. \& Jonas, J. (1976) J. Chem. Phys. 65, 1783-1788

Zhou, N., Bianucci, A. M., Pattabiraman, N. \& James, T. L. (1987) Biochemistry 26, 7905-7913

Received 19 August 1988/23 November 1988; accepted 30 November 1988 